\title{
The Effects of Menopause on Periodontal Tissue
}

\author{
Tuba Talo Yıldırım¹, Filiz Acun Kaya² \\ ${ }^{1}$ Research Assistant, Dicle University, Faculty of Dentistry, Department of Periodontology, Diyarbakır, TURKEY \\ ${ }^{2}$ Associate Professor, Dicle University, Faculty of Dentistry, Department of Periodontology, Diyarbakır, TURKEY
}

\section{Key Words}

Menopause, periodontal tissue, periodontal disease, sex steroid hormones

\author{
Correspondence: \\ Tuba TALO YILDIRIM \\ Dicle University, Faculty of Dentistry, \\ Department of Periodontology, \\ 21280 Diyarbakır, Turkey \\ e-mail: dt_talo@hotmail.com
}

\begin{abstract}
Periodontitis and gingivitis, a prevalent oral diseases, have been connected to several systemic health changes. The aim of this investigation was to review the effects of menopause on periodontal tissue. Epidemiologic studies have identified a number of risk factors and risk indicators for periodontal attachment loss, including demographic, socioeconomic, behavioural, genetic, and systemic factors. Menopause has also been associated with destructive periodontal disease in older women. The homeostasis of the periodontium involves complex multifactorial relationships. Oestrogen and progesterone are responsible for physiological changes in women at specific phases of their life. Menopause is associated with significant adverse changes in the orofacial complex.
\end{abstract}

(Int Dent Res 2011;3:81-86)
Periodontal disease refers to both gingivitis and periodontitis. Gingivitis is an inflammatory condition of the soft tissues surrounding the teeth. The main symptoms of gingivitis are redness, swelling and bleeding of gums. Gingivitis can often be controlled by removing the hard and soft deposits from the tooth surface (1). If unchecked, gingivitis progresses to periodontitis, an inflammation of the supporting tissues of the teeth, including the gingiva, alveolar bone, and periodontal ligament (2). Periodontitis is a chronic inflammatory process that occurs in response to a predominantly Gram-negative bacterial infection originating in dental plaque. Specific bacterial species, such as Porphyromonas gingivalis and Tannerella forsythensis, have been shown to be important in the aetiology of periodontitis (3).

The inflammatory response may result in ulceration of the gingiva, which might allow the entry of bacterial cells, their products (including lipopolysaccharides, or LPS; peptidoglycan fragments; and hydrolytic enzymes), or both into the systemic circulation (4). Research has demonstrated that the host response to periodontal infection results in the local production of cytokines and biological mediators such as prostaglandins and interleukins, as well as the systemic production of serum antibodies $(5,6)$. Periodontitis leads to progressive and irreversible loss of bone and periodontal ligament attachment, as inflammation extends from the gingiva into adjacent bone and ligament. Signs and symptoms of progressing periodontitis include red, swollen gums that may appear to have pulled away from the teeth, persistent bad breath, pus between the teeth and gums, and loose or separating teeth (2).

Epidemiologic studies have identified a number of risk factors and risk indicators for periodontal attachment loss (PAL), including demographic, 
socioeconomic, behavioural, genetic, and systemic factors $(1,2)$.

Menopause has also been associated with destructive periodontal disease in older women $(7,8)$. Peak ovarian function occurs before age 30 and then declines gradually. The menopause transition (climacteric, perimenopause), defined as the months and years surrounding the last menstrual period, is precipitated by fewer functioning follicles and ova, a consequent reduction in oestrogen level and an inability to respond to pituitary GnRH, FSH and LH. The initial sign of the transition, which may begin in the $40 \mathrm{~s}$, is a reduction in menstrual flow. This usually is followed by missed periods (9). Menopause is defined as the permanent cessation of menstruation due to loss of ovarian follicular function, and usually takes place between 45 and 55 years of age (10). Cigarette smoking is the only factor that has been consistently linked to earlier natural menopause. Julie reported that earlier onset of natural menopause among African American women is strongly associated with smoking and inversely associated with body mass index and oral contraceptive use $(11,12,13)$. Oral contraceptives $(14,15,16)$ low body mass index and low educational status (17) have also been associated with earlier menopause.

The physiological changes associated with menopause cause some women to experience uncomfortable symptoms. Postmenopausal women are at a higher risk of hypertension, pro-atherogenic lipid changes, diabetes, and severe cardiovascular disease, compared with their premenopausal counterparts (18). Multiple studies have demonstrated an association between postmenopausal status and increased levels of total cholesterol, low-density lipoprotein cholesterol (LDLC), lipoprotein(a), and decreased levels of highdensity lipoprotein-cholesterol (HDL-C) (19). Although premenopausal women are at a lower risk of heart disease than men, a twofold increase in risk of CVD follows menopause (20). Hot flushes have been recognized as a common menopausal symptom (21). This symptom is related to the central nervous system, or CNS. Oestrogen deficiency leads to dysregulation of the hypothalamic temperature control centre, resulting in vasomotor symptoms (9). Another symptom of menopause is night sweats. These vasomotor symptoms usually resolve spontaneously within two to four years of the last menses (22). Also, the postmenopausal period is associated with an increased risk of osteoporotic fractures, myocardial infarction, menstrual cycle disorders, vaginal dryness and possibly an early onset of Alzheimer's disease $(23,24)$.

Osteoporosis is defined as a skeletal disorder characterised by low bone mass and microarchitectural deterioration of bone tissue leading to enhanced bone fragility, with a consequent increase in fracture risk $(25,26)$. The primary risk factors related to the development of osteoporosis include female sex and increasing age, but other risk factors have been identified: early menopause (younger than 45 years), cigarette smoking, high alcohol consumption, lack of physical activity, thin body frame, race (Asian or white), low calcium intake, excessive caffeine intake, certain medications (such as glucocorticoids and cytotoxic drugs) and certain diseases (27).

Osteoperosis is a major cause of morbidity, mortality and medical expense. It affects an estimated 75 million people in the United States, Europe and Japan combined, including one in three postmenopausal women and a majority of elderly people (28). Oestrogen deficiency is responsible for bone loss in postmenopausal women (29). However, hormone replacement of an adequate dosage can slow or prevent bone loss $(30,31)$. Studies suggest that low oestrogen production after menopause is associated with increased production of interleukin 1 (IL-1), IL-6, IL-8, IL-10, tumour necrosis factor alpha, granulocyte colony-stimulating factor, and granulocyte-macrophage colony-stimulating factor, which stimulates mature osteoclasts, modulates bone cell proliferation, and induces resorption of both skeletal and alveolar bone $(32,33)$.

Burning mouth syndrome is characterized by a burning sensation on the tongue or at other oral sites, usually in the absence of clinical and laboratory findings. Affected patients often present with multiple oral complaints, including burning, dryness and taste alterations. Burning mouth complaints are reported more often in women, especially after menopause. Given in low dosages, benzodiazepines, tricyclic antidepressants or anticonvulsants may be effective in patients with burning mouth syndrome. Topical capsaicin has been used in some patients (34).

\section{Sex Steroid Hormones}

The homeostasis of the periodontium involves complex multifactorial relationships, in which the endocrine system plays an important role (35). Hormones are specific regulatory molecules that have potent effects on the major determinants of the development and integrity of the skeleton and oral cavity, including periodontal tissues (36). Hormones can be divided into four subgroups based upon their chemical structure: steroids, glycoproteins, polypeptides, and amines. Steroid sex hormones are derived from cholesterol and all have three rings of six carbon atoms each (37).

Oestrogen and progesterone are responsible for physiological changes in women at specific phases 
of their life: puberty, menstrual cycle, pregnancy, menopause, and post menopause (38). Oestrogen, progesterone and chorionic gonadotropin (during pregnancy) all affect the microcirculatory system, producing the following changes: swelling of endothelial cells and periocytes of the venules, adherence of granulocytes and platelets to vessel walls, formation of microthrombi, disruption of perivascular mast cells, increased vascular permeability, and vascular proliferation (39).

All natural androgens are derived from a 19carbon tetracyclic hydrocarbon nucleus known as androstane. One of the most potent androgenic hormones, testosterone (17-hydroxy-androst-4-en3-one), is synthesized by the Leydig's cells of the testes, the thecal cells of the ovary and the adrenal cortex. The biological activities of androgens can be observed in virtually every tissue of the body. The more important functions of androgens include: male sexual differentiation, development of adult male phenotype, facilitation of human sexual behaviour, and regulation of specific metabolic processes in the liver, kidneys, and salivary glands (35).

Androgens may play a significant role in the maintenance of bone mass (40) and inhibit osteoclastic function, inhibit prostaglandin synthesis and reduce interleukin- 6 (IL-6) production during inflammation (41). Also, androgens enhance matrix synthesis by periodontal ligament fibroblasts and osteoblasts (42).

Sex steroid hormones exert considerable influence, both directly and indirectly, on cellular differentiation, proliferation, and growth in target tissues. In the oral cavity, androgens, oestrogens and progestins are known to affect several cell types. Sex steroid hormone research has focused primarily on two cell groups, the keratinocyte and the fibroblast (35). Oestrogen inhibits the expression of inflammatory cytokines important in bone resorption, and oestrogen deficiency may contribute to more intense gingival inflammation during periodontitis and subsequent oral bone loss, and may result in bone loss at both oral and skeletal sites. A number of studies have suggested that the risk of postmenopausal tooth loss is reduced by oestrogen replacement (43). Furthermore, lower oestrogen levels have been linked to gingival inflammation (44) and reduced clinical attachment levels (45).

\section{Effects of Menopause on Periodontal Tissue}

Menopause is also associated with significant adverse changes in the orofacial complex. Women appear to experience an increase in oral symptoms that may result from endocrine disturbances (reduced estrogen), calcium and vitamin deficiency and various psychologic factors during their menopausal years $(46,47)$. They may complain of dry mouth because of decreased salivary secretion, as well as a burning sensation of the mouth and tongue. Taste sensation may change, causing frequent complaints of a metallic taste (48). Also during menopause, women may experience dysesthesia, dental caries, periodontitis and an osteoporotic jawbone unsuitable for conventional dental devices and implants (9).

Some women develop concurrent senile atrophic gingivitis, in which an abnormal paleness of the gingival tissues develops. Other people develop a condition known as menopausal gingivostomatitis, which is characterised by gingivae that are dry and shiny, bleed easily and range in colour from abnormally pale to erythematous (9).

Peri- or post-menopausal women take hormone replacement therapy (HRT) to relieve climacteric symptoms and increase their quality of life $(49,50)$. Hormone replacement in adequate dosage can slow or prevent bone loss (31). HRT includes oral administration, oestrogen containing dermal patches and tibolone (51). Marcos reported that the response to the HR therapy in periodontal disease is probably due to the existence of oestrogen receptors localized in the gingiva and the periodontal ligament (52). Some studies have suggested that postmenopausal women using HRT have increased tooth retention $(53,54)$ and decreased periodontal destruction $(7,55,56)$. Alex et al. found that postmenopausal HRT women had a two times greater likelihood of having periodontitis than premenopausal women. In contrast, postmenopausal HRT+ women did not have a greater chance of having periodontitis than premenopausal women. Although postmenopausal HRT- women showed significantly greater tooth loss than postmenopausal HRT+ women (57). Engeland et al. observed that premenopausal women aged 50 to 54 years healed similarly to women aged 18 to 43 years, whereas age-matched postmenopausal HRTwomen showed delayed healing. The data indicated that HRT may improve mucosal wound healing in postmenopausal women (58).

Osteoporosis is more common in women than in men. Women are at a greater risk for osteoporosis after menopause (59) because oestrogen levels decline rapidly, which may lead to systemic bone loss (60). Bone turnover rate is higher in alveolar bone than long bones. Therefore, it was suggested that a systemic imbalance in bone resorption and deposition might be manifested earlier in the alveolar process than in other sites (1). Kribbs reported that postmenopausal women with osteoporosis had decreased mandibular bone 
density, thinned cortex at the gonion, and more tooth loss than healthy postmenopausal women (61). The American Academy of Periodontology considers osteoporosis to be a risk factor for periodontal disease (62). A number of studies have investigated a possible relationship between periodontitis $(63,64)$. Tezal et al. found that low bone mineral density was related to loss of interproximal alveolar bone (the alveolar bone between adjacent teeth) and, to a lesser extent, ligamentous attachment loss (64). Lundstrom et al. showed no significant differences in periodontal conditions or marginal bone levels of 70 year-old women with osteoporosis, as compared to those with a normal bone mineral density (65). Oestrogen deficiency caused a decrease in trabecular bone volume around the implants and a decrease in contact between the implant and the trabecular bone (9). Recent studies using animal models have examined the effects of a paucity of oestrogen on the initial osseointegration of dental implants. These studies showed that when new implants (without functional occlusion) are placed in previously ovariectomized animals, the trabecular bone volume around the implant and contact between the implant and new trabecular bone are markedly decreased in comparison with nonovariectomized animals $(66,67)$.

Serum osteocalcin is presently considered a valid marker of bone turnover when resorption and formation are coupled and a specific marker of bone formation when formation and resorption are uncoupled (68). Bullon et al. reported that low serum osteocalcin concentration is associated with a significantly higher percentage of decrease in probing depth and clinical attachment level after periodontal treatment in postmenopausal women. Low saliva osteocalcin concentrations are significantly associated with a higher percentage of decrease in probing depth (69). Lorne et al. reported the therapeutic potential of long-term subantimicrobial-dose doxycyline therapy to reduce periodontal collagen breakdown and alveolar bone resorption in postmenopausal women (70).

Periodontal infections can increase the systemic release of inflammatory cytokines, which accelerate systemic bone resorption. Indeed, vitamin D deficiency has been associated with a cytokine profile that favours greater inflammation (e.g., higher levels of C-reactive protein and interleukin 6, and lower levels of interleukin 10), and vitamin D supplementation decreases circulating inflammatory markers. Therefore, Luca et al. suggest that menopausal women should maintain an adequate vitamin D status in order to prevent and treat osteoporosis-associated periodontal disease (71).

There is little knowledge of the prevalence of the periodontal microbiota among peri- and postmenopausal women (45). However, sex hormones have long been considered to affect periodontal tissues and periodontal disease progression $(72,73)$. Tarkila et al. reported that use of HRT did not correlate with periodontal health status, and led to lower numbers of samples positive for the periodontal pathogens $\mathrm{P}$. gingivalis and $\mathrm{T}$. forsythia. (74). Treatment of periodontal disease has been primarily directed towards a microbiological aetiology. Prevention of bone loss by modulating the host response to infection could be a new adjunctive method for the management of periodontitis (1). Bisphosphonates, the most commonly prescribed therapy for osteoporosis, inhibit systemic bone resorption (75).

Drugs that alter bone metabolism, such as oestrogen and bisphosphonate, were suggested by several case-control studies as a new approach to the treatment of periodontitis in postmenopausal patients (1).

This literature review highlights the importance of the effects of menopause on periodontal tissue.

\section{Acknowledgments}

The authors deny any conflicts of interest related to this study.

\section{References}

1. Kochman RH, Kochman T, Stabholz A, Celinkier $\mathrm{DH}$. Bisphosphonate and estrogen replacement therapy for postmenopausal periodontitis. Imaj 2004;6:173-7.

2. Buencamıno MC, Palomo L, Thacker HI. How menopause affects oral health and what we can do about it. Cleveland Clinic Journal of Medicine 2009; 76(8):467-75.

3. Brennan RM, Genco RJ, Wilding GE, Hovey KM, Trevisan M, Wactawski-Wende J. Bacterial Species in Subgingival Plaque and Oral Bone Loss in Postmenopausal. J Periodontol 2007;78:105161.

4. The American Academy of Periodontology, Committee on Research, Science, and Therapy. Periodontal disease as a potential risk factor for systemic diseases. J Periodontol 1998;69:841-50.

5. The American Academy of Periodontology. The pathogenesis of periodontal diseases. J Periodontol 1999;70:457-70.

6. Iacopino AM, Cutler CW. Pathophysiological relationships between periodontitis and systemic disease: recent concepts involving serum lipids. J Periodontol 2000;71:1375-84.

7. Payne JB, Reinhardt RA, Nummikoski PV, Patil KD. Longitudinal alveolar bone loss in 
postmenopausal osteoporotic/osteopenic women. Osteoporos Int 1999;10:34-40.

8. Geurs NC. Osteoporosis and periodontal disease. Periodontol 2000 2007;44:29-43.

9. Friedlander $\mathrm{AH}$. The physiology, medical management and oral implications of menopause. J Am Dent Assoc 2002;133:73-81.

10. Nikolaou D, Gilling-Smith C. Early ovarian ageing: Are women with polycystic ovaries protected? Hum Reprod 2004; 19:2175-79.

11. Palmer JR, Rosenberg L, Wise LA, Horton NJ, Adams-Campbell LL. Onset of natural menopause in African American Women Am J Public Health. 2003;93:299-306.

12. McKinlay SM, Brambilla DS, Posner JG. The normal menopause transition. Am J Hum Biol. 1992; 4: 37-46.

13. Hardy $R$, Kuh D, Wadsworth M. Smoking, body mass index, socioeconomic status and the menopausal transition in a British national cohort. Int J Epidemiol. 2000;29:845-51.

14. Gold EB, Bromberger J, Crawford S. Factors associated with age at natural menopause in a multiethnic sample of midlife women. Am J Epidemiol. 2001;153:865-74.

15. Stanford JL, Harge $P$, Brinton LA. Factors influencing the age at natural menopause. J Chronic Dis. 1987;40:995-1002.

16. Van Keep PA, Brand PC, Lehert P. Factors affecting the age at menopause. J Biosoc Sci. 1979;6:37-55.

17. Luoto R, Kaprio J, Uutela A. Age at natural menopause and sociodemographic status in Finland. Am J Epidemiol. 1994;139:64-76.

18. Polotsky HN, Polotsky AJ. Metabolic Implications of Menopause. Seminars In Reproductive Medicine 2010;28(5):426-34

19. Carr MC. The emergence of the metabolic syndrome with menopause. J Clin Endocrinol Metab 2003; 88(6): 2404-11.

20. Kannel WB. Metabolic risk factors for coronary heart disease in women: perspective from the Framingham Study. Am Heart J 1987;114(2):413-19.

21. Ko-En Huang. Menopause perspectives and treatment of Asian Women. Semınars in Reproductıve Medıcıne 2010;28(5): 396-403.

22. Johnson SR. Menopause and hormone replacement therapy. Med Clin North Am 1998;82:297-320.

23. Kenemans $P$, Van Unnik GA, Mijatovic $V$, Van Der Mooren MJ. Perspectives in hormone replacement therapy. Maturitas 2001; 38:41-8.

24. Paganini-Hill A. Oestrogen replacement therapy and Alzheimer's disease. Br J Obstet Gynaecol 1996;103:80-6.

25. Peck WA, Burkhardt $P$, Christensen $C$. Consensus development conference: diagnosis, prophylaxis and treatment of osteoporosis. Am J Med 1993;94:645-50.

26. NIH Consensus Development Panel. Osteoporosis prevention, diagnosis and therapy. JAMA 2001;285:785-95.

27. Cooper C, Melton LJ. Magnitude and impact of osteoporosis and fractures. In: Marcus R,
Feldman D, Kelsey J, eds. Osteoporosis. San Diego: Academic Press; 1996:419-34.

28. Peel N, Eastrell R. ABC of rheumatology. Osteoporosis. BMJ 1995;310:989-92.

29. Reginster JY, Sarlet N, Lecart MP. Fractures in osteoporosis: the challenge for the new millennium. Osteoporos Int 2005;16 (1):1-3.

30. Ettinger $B$. Use of low-dosage 17 betaestradiol for the prevention of osteoporosis. Clinical Therapeutics 1993; 15:950-62.

31. Allen IE, Monroe M, Connelly J, Cintron R. \& Ross, S. D. Effect of postmenopausal hormone replacement therapy on dental outcomes. Management Care Interface 2000;13:93-9.

32. Pacifici R. Estrogen, cytokines and pathogenesis of postmenopausal osteoporosis. J Bone Miner Res 1996;11:1043-51.

33. Pacifici R, Brown C, Pusheck E. Effect of surgical menopause and estrogen replacement on cytokine release from human blood mononuclear cells. Proc Natl Acad Sci USA 1991; 88:5134-8.

34. Grushka M, Epstein Jb, Gorsky M. Burning Mouth Syndrome. Am Fam Physician 2002;65:615-22.

35. Mariotti A. Sex steroid hormones and cell dynamics in the periodontium. Oral Biol Med 1994;5:27-53.

36. Güncü G, Tözüm T. The effects of estrogen, progesterone and testosterone on periodontal tissues. G.Ü. Dişhek. Fak. Derg. 2005;22(2):121127.

37. Mascarenhas $\mathrm{P}$, Gapski R, Al-Shammari K, Wang $\mathrm{H}-\mathrm{L}$. Influence of sex hormones on the periodontium. J Clin Periodontol 2003;30:671-81.

38. Amar $\mathrm{S}$, Chung KM. Influence of hormonal variation on the periodontium in women. Periodontology 2000 1994;6:79-87.

39. Krejci CB, Bissada NF. Women's health issues and their relationship to periodontitis J Am Dent Assoc 2002; 133:323-9.

40. Morley JE. Testosterone in contemporary endocrinology: endocrinology of aging. eds. 2000; p. 127149. Totowa, NJ: Humana Press Inc.

41. Güncü GN, Tözüm TF, Çağlayan F. Effects of endogenous sex hormones on the periodontium. Australian Dental Journal 2005;50:(3):138-145.

42. Kasperk $\mathrm{CH}$, Wergedal JE, Farley JR. Androgens directly stimulate proliferation of bone cells in vitro. Endocrinology 1989;124:1576-8.

43. Lerner UH. Inflammation-induced bone remodeling in periodontal disease and the influence of postmenopausal osteoporosis. J Dent Res 2006;85:596-607.

44. Norderyd OM, Grossi SG, Machtei EE, Zambon JJ, Hausmann E, Dunford RG. Periodontal status of women taking postmenopausal estrogen supplementation. J Periodontol 1993;64:957-62.

45. Reinhardt RA, Payne JB, Maze CA, Patil KD, Gallagher SJ, Mattson JS. Influence of estrogen and osteopenia/osteoporosis on clinical periodontitis in postmenopausal women. J Periodontol 1999;70:823-8.

46. Frutos R, Rodriguez S, Miralles-Jorda L, Machuca G. Oral manifestations and dental treatment in menopause. Med Oral. 2002;7(1):26-30,31-5. 
47. Sewon $L$, Laine $M$, Karjalainen $S$, LeimolaVirtanen R, Hiidenkari T, Helenius $H$. The effect of hormone replacement therapy on salivary calcium concentrations in menopausal women. Arch Oral Biol. 2000;45(3):201-6.

48. Rose $F L$, Kaye D. Internal medicine for dentistry. In: chapter 14 endocrinology. Ed. Bartuska DG. 2nd Ed. St lois. Mosby Company 1990;1075.

49. Wiklund I, Karlberg J, Mattsson LA. Quality of life of postmenopausal women on a regimen of transdermal estradioltherapy: a double-blind placebo-controlled study. Am J Obstet Gynecol 1993;168:824-30.

50. Limouzin-Lamothe MA, Mairon N, Joyce CR, Le Gal M. Quality of life after the menopause: influence of hormonal replacement therapy. Am J Obstet Gynecol 1994;170:618-24.

51. Ederveen AG, Kloosterboer HJ. Tibolone, a steroid with a tissue-specific hormonal profile, completely prevents ovariectomy-induced bone loss in sexually mature rats. J Bone Miner Res 1999;14:1963-70.

52. López Marcos JF, García Valle S, García Iglesias AA. Periodontal aspects in menopausal women undergoing hormone replacement therapy. Med Oral Patol Oral Cir Bucal 2005;10:132-41.

53. Grodstein F, Colditz GA, Stampfer MJ. Postmenopausal hormone use and tooth loss: A prospective study. J Am Dent Assoc 1996;127:370-7.

54. Taguchi A, Sanada M, Suei Y. Effect of estrogen use on tooth retention, oral bone height, and oral bone porosity in Japanese postmenopausal women. Menopause 2004;11:556-62.

55. Grossi SG. Effect of estrogen supplementation on periodontal disease. Compend Contin Educ Dent Suppl 1998;(22):30-6.

56. Wactawski-Wende J, Hausmann E, Hovey K, Trevisan M, Grossi S, Genco RJ. The association between osteoporosis and alveolar crestal height in postmenopausal women. J Periodontol 2005;76:2116-24.

57. Haas AN, Rösing CK, Oppermann RV, Albandar JM, Susin J. Association among menopause, hormone replacement therapy, and periodontal attachment loss in Southern Brazilian Women J Periodontol 2009; 80:1380-7.

58. Engeland CG, Sabzehei B, Marucha PT. Sex hormones and mucosal wound healing. Brain Behav Immun 2009;23:629-35.

59. Derviş E. Oral implications of osteoporosis. Oral Surg Oral Pathol Oral Radiol Endod 2005;100:349-56.

60. North American Menopause Society. Menopause Practice: A Clinician's Guide. 3rd ed; 2007.

61. Kribbs PJ. Comparison of mandibular bone in normal and osteoporotic women. J Prosthet Dent 1990;63:86-9.

62. American Dental Association Council on Access, Prevention and Interprofessional Relations. Women's Oral Health Issues. November 2006.

63. Jeffcoat $M K$, Lewis CE, Reddy MS, Wang CY, Redford M. Postmenopausal bone loss and its relationship to oral bone loss. Periodontol 2000 2000;23:94-102.
64. Tezal M, Wactawski-Wende J, Grossi SG, Ho AW, Dunford R, Genco RJ. The relationship between bone mineral density and periodontitis in postmenopausal women. J Periodontol 2000;71:1492-8.

65. Lundström A, Jendle J, Stenström B,Toss G, Ravald N. Periodontal conditions in 70 year old women with osteoporosis. Swed Dent J 2001;25:89-96.

66. Motohashi M, Shirota T, Tokugawa Y, Ohno K, Michi K, Yamaguchi A. Bone reactions around hydroxyapatite-coated implants in ovariectomized rats. Oral Surg Oral Med Oral Pathol Oral Radiol Endod 1999;87:145-52.

67. Yamazaki M, Shirota T, Tokugawa Y. Bone reactions to titanium screw implants in ovariectomized animals. Oral Surg Oral Med Oral Pathol Oral Radiol Endod 1999;87:411-8.

68. Giannobile WV, Al-Shammari KF, Sarment DP. Matrix molecules and growth factors as indicators of periodontal disease activity. Periodontol 2000 2003;31:125-34.

69. Bullon P, Chandler L, Segura Egea JJ, Perez Cano R, Martinez Sahuquillo A. Osteocalcin in serum, saliva and gingival crevicular fluid: their relation with periodontal treatment outcome in postmenopausal women Med Oral Patol Oral Cir Bucal 2007;12:193-7.

70. Golub LM, Lee HM, Stoner JA, Sorsa T, Reinhardt RA, Wolff MS, Ryan ME, Nummikoski PV, Payne JB. Subantimicrobial-dose doxycycline modulates gingival crevicular fluid biomarkers of periodontitis in postmenopausal osteopenic women. J Periodontol. 2008;79(8):1409-18.

71. Mascitelli L, Pezzetta F, Goldsteın MR. Menopause, vitamin D, and oral health. Cleveland clinic journal of medicine 2009;76(11):629-30.

72. Sooriyamoorthy M, Gower DB. Hormonal influences on gingival tissue: relationship to periodontal disease. Review Article. J Clin Periodontol 1989, 16:201-8.

73. Carrillo-de-Albornoz A, Figuero A, Herrera D, Bascones-Martinez A. Gingival changes during pregnancy: II. Influence of hormonal variations on the subgingival biofilm. J Clin Periodontol 2010,37:230-40.

74. Tarkkila L, Kari K, Furuholm J, Tiitinen A, Meurman $\mathrm{JH}$. Periodontal disease-associated micro-organisms in peri-menopausal and postmenopausal women using or not using hormone replacement therapy. A two-year follow-up study BMC Oral Health 2010;10(10):1-8.

75. Chestnut $\mathrm{CH}$, Skag A, Christiansen C. Effects of oral ibandronate administered daily or intermittently on fracture risk in postmenopausal osteoporosis. J Bone Miner Res 2004; 19:1241-9. 